\title{
Using Calculus to Plan an Open-Air Concert
}

Timur Kalandarov

University of South Florida

\author{
Advisors: \\ Arcadii Grinshpan, Mathematics and Statistics \\ Yen Thi Hai Pham, Physics \\ Problem Suggested By: Timur Kalandarov
}

Follow this and additional works at: https://digitalcommons.usf.edu/ujmm

Part of the Mathematics Commons

UJMM is an open access journal, free to authors and readers, and relies on your support: Donate Now

\section{Recommended Citation}

Kalandarov, Timur (2021) "Using Calculus to Plan an Open-Air Concert," Undergraduate Journal of Mathematical Modeling: One + Two: Vol. 12: Iss. 1, Article 4.

DOI: https://doi.org/10.5038/2326-3652.12.1.4939

Available at: https://digitalcommons.usf.edu/ujmm/vol12/iss1/4 


\title{
Using Calculus to Plan an Open-Air Concert
}

\begin{abstract}
A concert is a mass entertainment event held indoors, at concert halls, or outdoors (open-air festivals). These two formats differ greatly from each other. However, the goal of both events remains the same - to allow the audience to enjoy the musical performance. Indoor halls are designed for the best acoustics of sound. They are often circular and let sound waves travel around the inside of the building, like an echo bouncing back and forth. This makes the audience feel like they are surrounded by sound. Such places already have outlined spots for mounting music equipment with the highest efficiency. Thus, thanks to the fact that the building is engineered exactly for the purpose of conserving the sound, concert holders are not obligated with extra calculations and planning. On the other hand, open-air concerts can range from small, acoustic gatherings at municipal parks, to large music festivals that take place over several days and feature a large number of different artists. Such concerts take great amounts of planning to make sure that the stage is visible and, more importantly, audible from the entire seating area.

In this paper, we investigate the physics of sound events of both formats and derive a basic formula for calculating the coverage of a sound system.
\end{abstract}

\section{Keywords}

COVID-19, Sound Pressure Level (SPL), Inverse Square Law, Line Array Principle, Law of Logarithmic Addition of Sound Levels, infinite series

\section{Creative Commons License}

(c) (i) (2)

This work is licensed under a Creative Commons Attribution-Noncommercial-Share Alike 3.0 United States License. 


\section{PROBLEM STATEMENT}

What should be the loudness (sound pressure level, $S P L$ ) of a sound system at an open-air concert so that the coverage of the system would allow entire audience, including listeners from the farthest stands, to enjoy the music.

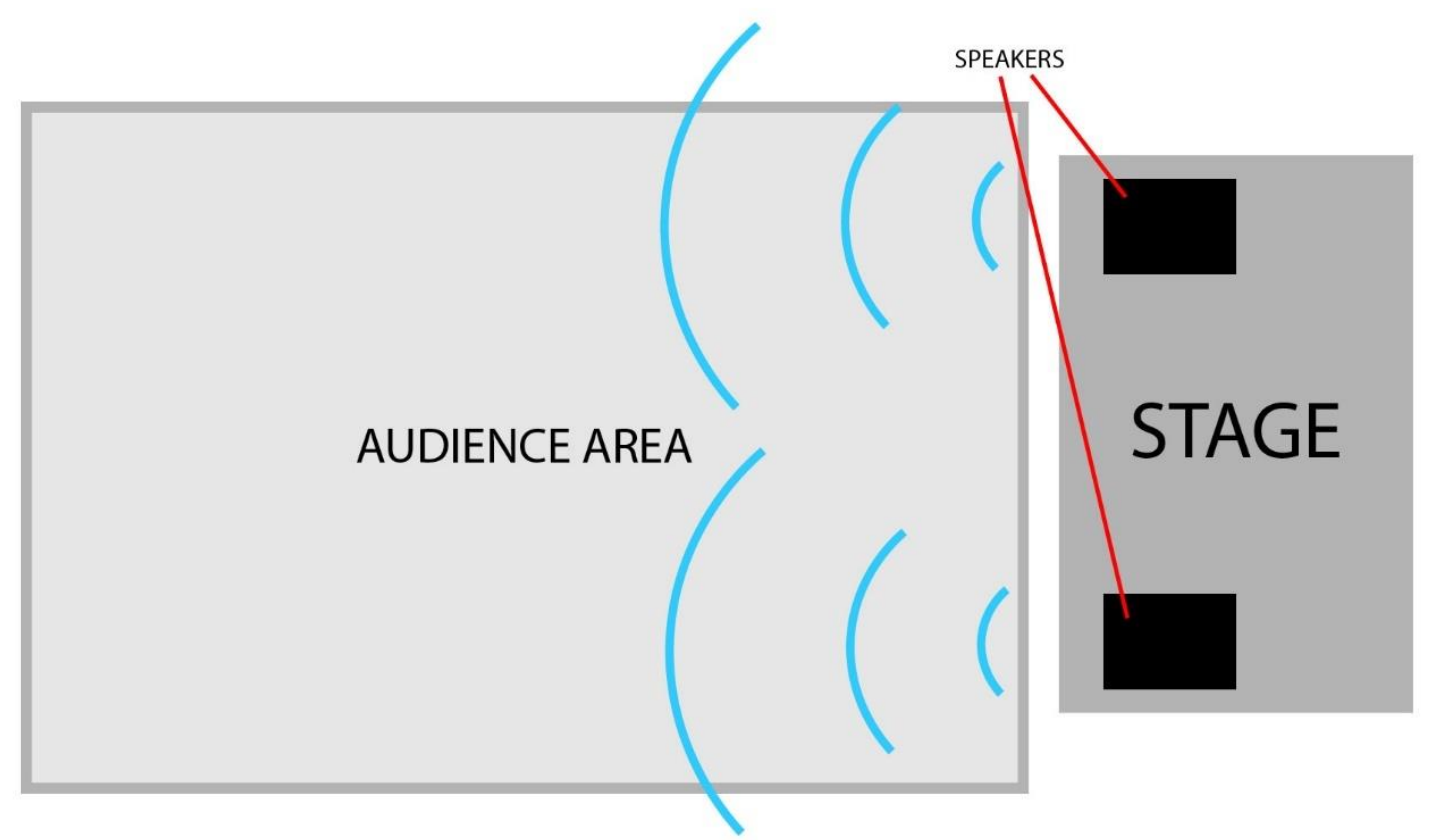

Figure 1: Example Plan of an Open-Air Concert

\section{MOTIVATION}

It is 2021 now, and humanity is just about to get vaccinated against the COVID-19 virus that brought so many restrictions to our life. Step-by-step, life is returning to normal, and we see a positive tendency of rising entertainment activity. However, huge overcrowded indoor events are still a hazardous place to be. In light of this, outside, where the air is naturally circulating and 
it is easier for airborne contaminants to disperse, is a good solution for holding a big gathering (Shukman).

Nonetheless, an outdoor loud gathering is not an easy event to prepare for. Many open-air concerts are very loud, and without the insulation of a building or arena to contain the noise, this also takes an amount of planning, to assure that the concert does not bother the neighbors. Many areas have noise regulations, and it is sometimes a challenge to calculate the required distance from residential areas and pick the right spot (see Figure 1).

\section{DISCUSSION}

In terms of this paper, we refer to sound as a mechanical wave that results from the backand-forth vibration of the particles of air. The sound travels through our ears until it changes into an electrical signal and is sent to the brain via the auditory nerve. That makes the goal of acoustics - to make sound waves reach our ears with minimum damping.

Good indoor acoustics is built upon several factors: the shape of the building, material of the walls and furniture, no external sounds, and, of course, the right audio equipment.

The shape of the building gives a direction to a sound wave. The most popular and efficient shapes are circular, also called fan-shaped, and rectangular, called shoebox (Lu et al.). Sound travels back and forth around the room as it hits the obstacles and gets reflected or absorbed. 
The material of the obstacle that sound waves collide with defines a lot. When a sound wave strikes a surface of a certain material, it is either reflected or penetrates the material. If the surface of the obstacle is hard, then the acoustic impedance of this material is high, and the sound waves will be reflected. On the other hand, objects with a soft surface have low acoustic impedance and make sound waves penetrate the material without being absorbed.

It is rather hard to avoid the appearance of external sounds. Sound waves of different origins may result in wave interference. When two or more sound waves occupy the same space, they move through each other creating a different noise. In the case of acoustic halls, interference may be caused by the hum of the crowd.

The nature of the sound plays a major role in the whole experience. It should not be too loud or too quiet, louder than the sounds of the audience, and quieter than the threshold when the sound becomes painful. On top of this, each listener must be able to enjoy the music in full at all areas of the building.

When the venue is held outside, the situation gets more difficult. There are no walls to reflect sound waves around, the material of the objects around is arbitrary, sounds of the outer world never stop, and there are neighbors whom we cannot disturb while making sure that the performance is well-audible even for the farthest listeners.

\section{MATHEMATICAL DESCRIPTION AND SOLUTION APPROACH}

We select three factors that are relevant to the theme of music concerts and have the biggest impact on the acoustic experience: 
1. Theoretical coverage of a sound source

2. Impact of background noise on the effectiveness of the source

3. Usage of several sound sources

\section{Theoretical coverage of a sound source}

Loudness is described as Sound Pressure Level (SPL) and is measured in $d B$ (decibels). In order to determine an estimate of $S P L$ at a distance, the Inverse Square Law can be used. It says that $S P L$ decreases inversely with the square of the distance from the source at a rate of approximately $6 d B$ for each doubling of the distance:

$$
S P L(d)=S P L_{0}-20 \log _{10}(d)
$$

where $d$ is the distance in meters, and $S P L_{0}$ is a sound pressure level at one meter from the source (see Table 1).

Taking $S P L_{0}$ for zero, we can get the expression of change in $S P L$ for distance $d$ (see Figure 2):

$$
\Delta S P L(d)=-20 \log _{10}(d)
$$

Also we can consider the values of function (1) for $d=1,2, \ldots$ as terms of the following infinite series:

$$
\sum_{d=1}^{\infty}\left[S P L_{0}-20 \log _{10}(d)\right]
$$

Since $S P L_{0}$ is a constant and $\lim _{d \rightarrow \infty}\left[-20 \log _{10}(d)\right]=-\infty$, the series is divergent, which "explains" the pressure attenuation. 
It is important to outline, however, that the Inverse Square Law considers perfect conditions (no reflections, obstacles, and disturbances). For effective usage, we combine it with several other theorems and factors.

\section{Impact of background noise on the effectiveness of the source}

One of the acoustics laws is that for the sound to be audible and well-distinguished, its $S P L$ must be $5 d B$ higher than the noise of the environment. It means that if the ambient noise is equal to $60 \mathrm{~dB}$, the effective $S P L$ for a sound source should be $65 \mathrm{~dB}$ :

$$
S P L_{\text {ambient }}+5 d B \leq S P L_{\text {effective }}
$$

where $S P L_{\text {ambient }}$ is loudness of the environment and $S P L_{\text {effective }}$ is the minimum distinguishable loudness (see Table 2 for comparison of noise levels).

\section{Usage of several sound sources}

Almost all of the concerts utilize more than one speaker based on a principle called Line Array (see Figure 3). A line array system is made up of several identical loudspeakers connected vertically and synchronized together, to create a near-line source of the sound. The main purpose of this is not to increase loudness but rather expand the angle of vertical propagation of sound waves (see Figure 4).

Although the increase in loudness is relatively small, it cannot be ignored. According to the Law of Logarithmic Addition of Sound Levels, the resultant sound pressure level $S P L_{\text {total }}$ of multiple sources is equal to the logarithmic sum of their SPLs:

$$
S P L_{\text {total }}=10 \log _{10}\left(10^{S P L_{1}} 10 \frac{S P L_{2}}{10}+\cdots+10^{\frac{S P L_{n}}{10}}\right)=10 \log _{10}\left(\sum_{n} 10^{\frac{S P L_{n}}{10}}\right)
$$


But in our case, we add decibels of identical sound sources, so the formula can be simplified to:

$$
S P L_{\text {total }}=10 \log _{10}\left(n \times 10^{S P L / 10}\right)
$$

where $n$ is the number of identical sound sources.

Thus, the change in loudness with each additional sound source can be calculated as:

$$
\triangle S P L=10 \log _{10}(n)
$$

We can ensure that the formula (6) is divergent by finding its limit:

$$
\lim _{n \rightarrow \infty} 10 \log _{10}(n)=+\infty
$$

\section{Answering the Question}

Finally, combining the Inverse Square Law, $5 \mathrm{~dB}$ theorem, and the Line Array Principle, we deduce that:

$$
S P L_{\text {ambient }}+5 d B \leq S P L_{\text {total }}-20 \log _{10}(d)
$$

from which we can express the effective distance of the sound source $d$ :

$$
d \leq 10^{\left(S P L_{\text {total }}-S P L_{\text {ambient }}-5 d B\right) / 20}
$$

This is the answer to the question. 


\section{CONCLUSIONS AND RECOMMENDATIONS}

Acoustics is a vast and interesting field of study. It is quite difficult and even almost impossible to precisely predict the travel of numerous sound waves as the music plays. Even though this paper covers fundamental principles practices by engineers and event planners, it is extremely simplified. Some omitted factors are environmental conditions (wind, air temperature, and humidity), sound absorption, the subjectiveness of an individual's perception of loudness, and much more. The outcome of the present work is effective in an open space, mild weather conditions, and when the loudness of a sound source is relatively big to that of disturbing factors.

\section{NOMENCLATURE}

$d B:$ decibel

SPL (Sound Pressure Level) is measured in $d B$ (decibels)

$m$ meter

$d$ is the distance in meters

\section{REFERENCES}

"Comparative Examples of Noise Levels.” IAC Acoustics, 18 Mar. 2021, www.iacacoustics.com/blog-full/comparative-examples-of-noise-levels.html.

Lu, Shuai, et al. "The Influence of Shape Design on the Acoustic Performance of Concert Halls from the Viewpoint of Acoustic Potential of Shapes." Acta Acustica United with Acustica, vol. 102, no. 6, 2016, pp. 1027-1044., doi:10.3813/aaa.919017.

Shukman, David. "Covid: Can You Catch the Virus Outside?" BBC News, BBC, 22 Apr. 2021, www.bbc.com/news/explainers-55680305. 


\section{APPENDIX}

Table 1: Example of Loudness Attenuation of a Loudspeaker with initial SPL of $100 \mathrm{~dB}$

\begin{tabular}{|l|l|}
\hline Distance, $m$ & SPL, $d B$ \\
\hline $\mathbf{1}$ & 100 \\
\hline $\mathbf{2}(\mathbf{1} \boldsymbol{m}$ doubled) & 94 \\
\hline $\mathbf{3}$ & 90.5 \\
\hline $\mathbf{4}(\mathbf{2} \boldsymbol{m}$ doubled) & 88 \\
\hline
\end{tabular}

Table 2: Comparative Examples of Noise Levels

\begin{tabular}{|c|c|c|}
\hline SPL & Noise Source & Decibel Effect \\
\hline $\mathbf{0}$ & None & $\begin{array}{c}\text { hearing threshold for the } \\
\text { human ear }\end{array}$ \\
\hline $\mathbf{1 0}$ & Breathing & Barely audible \\
\hline $\mathbf{3 0}$ & Quiet rural area & Very quiet \\
\hline $\mathbf{5 0}$ & $\begin{array}{c}\text { Quiet suburb, conversation at } \\
\text { home }\end{array}$ & $1 / 4$ as loud as $70 d B$ \\
\hline $\mathbf{7 0}$ & $\begin{array}{c}\text { Passenger car at } 65 \text { mph at } 25 \\
f t(77 d B) ; \text { Radio or TV- } \\
\text { audio, vacuum cleaner }(70 \\
d B)\end{array}$ & $\begin{array}{c}\text { Upper 70s are annoyingly } \\
\text { loud to some people }\end{array}$ \\
\hline $\mathbf{8 0}$ & $\begin{array}{c}\text { Garbage disposal, } \\
\text { dishwasher, average factory }\end{array}$ & $\begin{array}{c}\text { Possible damage in 8-hour } \\
\text { exposure }\end{array}$ \\
\hline & $\begin{array}{c}\text { Steel mill, auto horn at } 1 \\
\text { meter, live rock music }(108- \\
114 d B) .\end{array}$ & $\begin{array}{c}\text { Average human pain } \\
\text { threshold }\end{array}$ \\
\hline
\end{tabular}

Source: "Comparative Examples of Noise Levels." IAC Acoustics, 18 Mar. 2021, www.iacacoustics.com/blog-full/comparative-examples-of-noise-levels.html. 
Table 3: Change of SPL for $n$ Sources of Sound

\begin{tabular}{|l|l|}
\hline Number of n equal sound sources & SPL increase $\triangle S P L$ \\
\hline $\mathbf{1}$ & 0 \\
\hline $\mathbf{2}$ & 3.0 \\
\hline $\mathbf{3}$ & 4.8 \\
\hline $\mathbf{4}$ & 6.0 \\
\hline $\mathbf{5}$ & 7.0 \\
\hline $\mathbf{6}$ & 7.8 \\
\hline $\mathbf{7}$ & 8.5 \\
\hline $\mathbf{8}$ & 9 \\
\hline $\mathbf{9}$ & 9.5 \\
\hline $\mathbf{1 0}$ & 10 \\
\hline
\end{tabular}




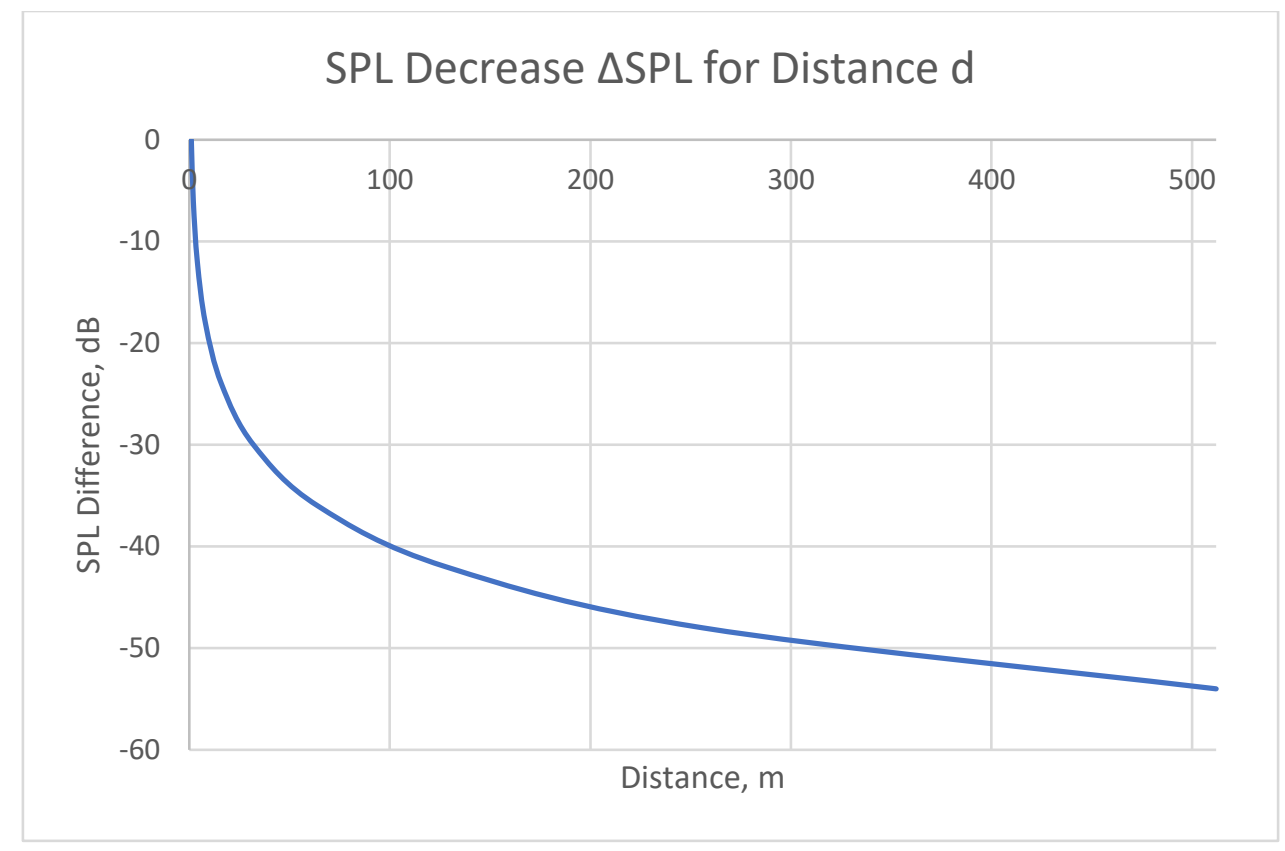

Figure 2: Reduction in SPL Based on Inverse Square Law

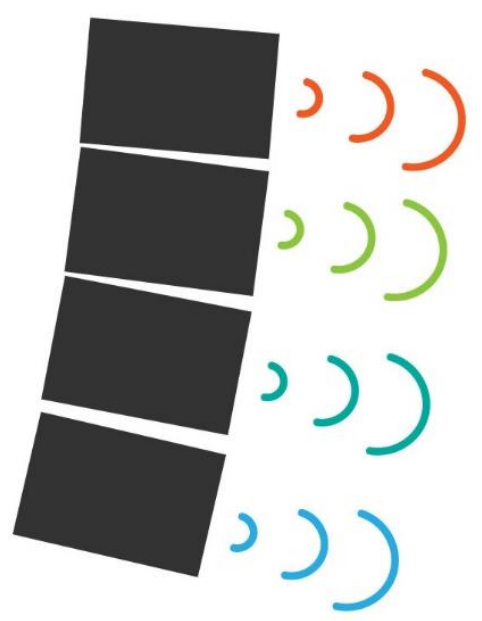

Figure 3: Example of Line Array Principle 


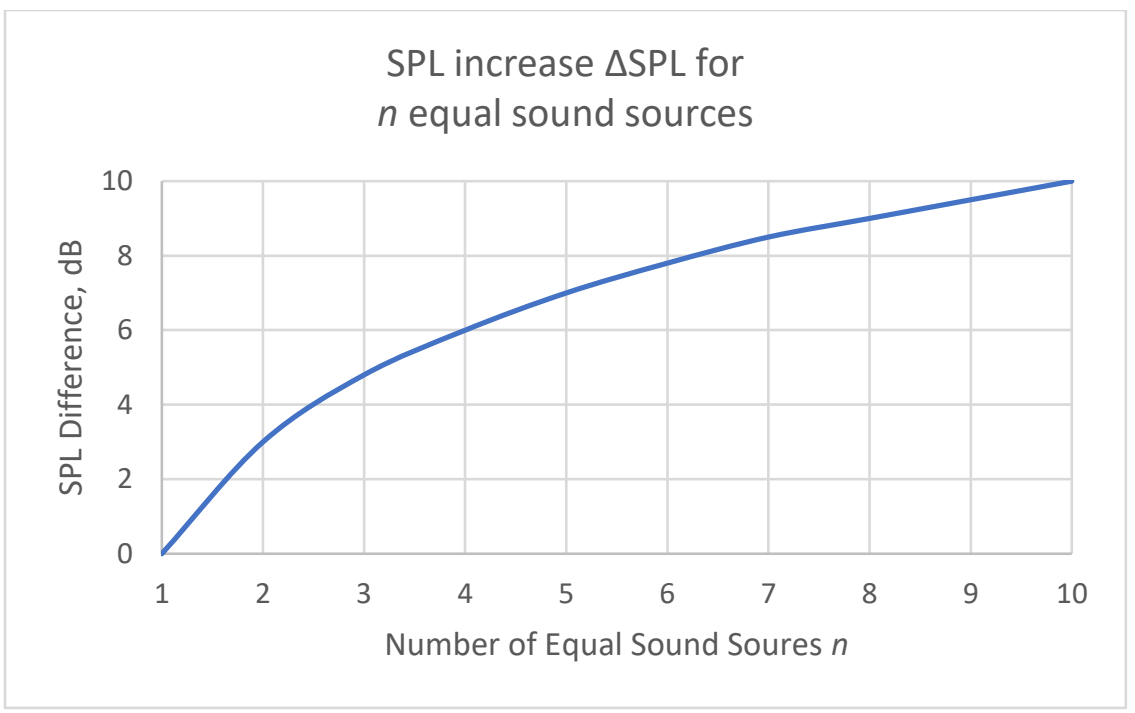

Figure 4: Adding of Equal Sound Sources 